\title{
Beyond chemotherapy: new agents for targeted treatment of lymphoma
}

\author{
Anas Younes \\ Department of Lymphoma and Myeloma, Unit 429, The University of Texas M. D. Anderson \\ Cancer Center, 1515 Holcombe Boulevard, Houston, TX 77030, USA ayounes@mdanderson.org
}

\begin{abstract}
An improved understanding of the molecular biology of cancer cell growth and survival and the role of the microenvironment in supporting the survival of cancer cells, including lymphoma cells, has led to the identification of a number of potential therapeutic targets. Despite these advances, drug development for lymphoma remains slow, inefficient, and frequently unfocused. Future work should focus on identifying 'driver' molecular defects of oncogenic pathways that can be targeted therapeutically, discovering predictive biomarkers for treatment response, and prioritizing promising drugs to accelerate their approval. This Review summarizes the current development status of novel agents for lymphoma and discusses strategies to move the field forward.
\end{abstract}

\section{Introduction}

In 2009 , about 74,000 people in the USA were diagnosed as having lymphoma, and approximately 21,000 deaths from the disease were reported. ${ }^{1}$ Current frontline treatment regimens include radiotherapy and chemotherapy, such as CHOP (cyclophosphamide, doxorubicin, vincristine, and prednisone) with or without the monoclonal antibody (mAb) rituximab. ${ }^{2}$ Advances in understanding the molecular biology of lymphoma have led to the identification of several potential therapeutic targets. As a result, new agents have been developed and approved by the FDA. However, the process of approving new drugs for lymphoma remains slow and inefficient. Of 53 new applications involving 39 different hematology and oncology drugs approved by the FDA between 2005 and 2007, only two drugs (bortezomib and vorinostat) were approved for the treatment of lymphoma. ${ }^{3}$ Since 2007 , three drugs (bendamustine, pralatrexate, and romidepsin) have been approved for patients with relapsed non- Hodgkin lymphoma. Remarkably, all five drugs were approved on the basis of results of non-randomized, phase II studies, and none have demonstrated improvement in overall survival.

Many drugs evaluated in phase I studies for lymphoma have been discontinued because they lack efficacy or have unacceptable toxic effects. Furthermore, although the number of phase II studies continue to increase, many trials lack focus, do not significantly advance the field, and compete for a relatively small pool of eligible patients. How to advance drugs with promising clinical activity from early, small phase I and II studies to large-scale pivotal trials remains a challenge. Moreover, lymphoma has more than 40 distinctive histological subtypes with different natural histories, varying cure rates, and heterogeneous underlying molecular defects; thus, the development of molecular targeted therapy for lymphoma is

(C) 2011 Macmillan Publishers Limited. All rights reserved

Supplementary information is linked to the online version of the paper at www.nature.com/nrclinonc

Competing interests The author declares no competing interests. 
more challenging than for any other type of cancer. Here, promising new targeted therapies for lymphoma and potential strategies to accelerate the development of new agents are discussed. This Review focuses on mAbs that target cell surface receptors and smallmolecule inhibitors that are involved in oncogenic processes.

\section{Targeted monoclonal antibodies}

\section{Unconjugated antibodies}

In 1997, the FDA approved the first unconjugated (naked) $\mathrm{mAb}$ - rituximab — for the treatment of relapsed CD20 $0^{+}$B-cell lymphoma. Several naked mAbs have since been developed to target other surface antigens and receptors expressed in patients with Hodgkin lymphoma and non-Hodgkin lymphoma, but with limited success. To date, three naked mAbs (rituximab, ofatumumab, and alemtuzumab) and two radioimmuno mAbs (ibritumomab tiuxetan and ${ }^{131}$ I-tositumomab) have been approved by the FDA for the treatment of B-cell lymphoid malignancies, and all but one of these target the CD20 antigen. ${ }^{4,5}$

\section{B-lineage antigens}

CD20 is an ideal target for $\mathrm{mAb}$ therapy because its expression is restricted to benign and malignant B lymphocytes. Rituximab has demonstrated single-agent activity in a wide variety of B-cell lymphoid malignancies, but its efficacy improved when combined with chemotherapy regimens, especially with CHOP in previously untreated patients with diffuse large B-cell lymphoma (DLBCL). ${ }^{6}$ Nonetheless, the CD20 antigen remained unchallenged as a target for mAb therapy for more than a decade.

Ofatumumab, a second-generation fully human anti-CD20 antibody, binds to a different small-loop epitope of CD20 compared with rituximab and elicits rapid and efficient in vitro cell lysis via complement-dependent cytotoxicity. ${ }^{5,7}$ Although ofatumumab demonstrated a $58 \%$ single-agent overall response rate (ORR) in patients with relapsed chronic lymphocytic leukemia (CLL) it failed to induce significant remissions in rituximab-refractory patients. ${ }^{8}$ In patients with relapsed follicular lymphoma, ofatumumab produced a $42 \%$ response rate, which is comparable to what has been previously reported with rituximab. ${ }^{7,9}$ Anti-CD20 naked mAbs, including GA101, veltuzumab, and ocrelizumab are in clinical development; however, it remains to be seen how these mAbs compare with rituximab. Although CD20 expression is prominent in a variety of B-cell lymphomas, many patients do not respond to anti-CD20 antibodies, indicating that CD20 expression alone is not sufficient to predict response to therapy. ${ }^{10}$ Thus, the benefits of newer mAbs are likely to be marginal unless specific mechanisms of resistance to anti-CD20 antibodies are addressed.

Expression of CD22 and CD23 antigens are also restricted to B lymphocytes and are being explored as therapeutic targets. Unlike CD20, CD22 is rapidly internalized, making it more suitable for antibody-drug conjugate (ADC) strategies than for naked antibody strategies. Unsurprisingly, epratuzumab-a naked IgG1 humanized anti-CD22 mab-is less effective than rituximab for the treatment of B-cell lymphomas (Table 1). ${ }^{11} \mathrm{CD} 23$ has been targeted using the mAb lumiliximab in patients with relapsed CLL; no major objective responses were observed in these patients. ${ }^{12}$ There are no data on lumiliximab activity in patients with B-cell lymphoma.

The CD19 antigen is highly expressed on B cells and is also internalized, but at a slower rate than CD22. Several strategies have been developed to target CD19 in patients with B-cell lymphoma, including blinatumomab - a bispecific T-cell engager-that targets CD19 and $\mathrm{CD} 3$ antigens. ${ }^{13}$ One advantage of this novel strategy is the use of activated $\mathrm{CD} 3{ }^{+} \mathrm{T}$ cells to kill the malignant $\mathrm{CD} 19^{+} \mathrm{B}$ cells, bypassing the need for specialized effector cells. ${ }^{14}$ 
Another advantage of blinatumomab is its lower molecular weight compared with fulllength mAbs, which improves penetration into the tumor. Ongoing phase I and II clinical trials have demonstrated promising clinical activity of blinatumomab in patients with relapsed B-cell follicular lymphoma and mantle-cell lymphoma (MCL); one such study reported that 11 of 12 patients achieved major clinical responses. ${ }^{15}$ Similarly, 13 of 16 patients with acute lymphoblastic leukemia achieved complete molecular remissions. ${ }^{16}$ Blinatumomab is administered as continuous intravenous infusions over several weeks. Despite the promising clinical activity of this agent, early trials were associated with unusual neurotoxicity, including coma, which may present challenges for its development. Finally, there are no data on the clinical activity of naked anti-CD19 antibodies, although these antibodies have recently entered clinical trials, the results of which are highly anticipated.

Antibodies that target B-cell antigens are likely to be used in combination with rituximab. Whether combining two antibodies that target B-cell antigens is a better strategy than using either one alone remains under investigation. Early clinical trials suggested only a marginal benefit when rituximab was combined with epratuzumab ${ }^{17}$ (Table 1) or when they were both combined with CHOP chemotherapy in patients with newly diagnosed DLBCL. ${ }^{18}$ It will be important to determine whether the effects of more than one antibody targeting different B-lineage antigens would be additive or noncross-resistant. A randomized study comparing rituximab plus $\mathrm{CHOP}$ (R-CHOP) with epratuzumab plus $\mathrm{CHOP}$ is under way to address this issue (clinicaltrials.gov NCT00451178).

\section{TNF receptor superfamily members}

Tumor necrosis factor (TNF) receptor superfamily members are being explored as potential targets for lymphoma therapy, even though many of these receptors are expressed outside the lymphatic system. ${ }^{19} \mathrm{TNF}$ receptor superfamily members regulate survival, inflammation, and immunity. Thus, antibodies that target these receptors that are involved in so many important cellular processes should take these properties into consideration.

Preclinical experiments have provided an elegant ration ale for targeting CD40 in lymphoid malignancies; ${ }^{19}$ however, emerging results from phase I and II clinical trials have demonstrated marginal single-agent activity. For example, dacetuzumab (SGN-40), a humanized anti-CD40 mAb with partial agonistic activity, produced an ORR of only $10 \%$ in 46 patients with relapsed DLBCL. ${ }^{20,21}$ The anti-CD40 antibody, HCD122, is currently being evaluated in a phase I study in patients with relapsed B-cell non-Hodgkin lymphoma and Hodgkin lymphoma, and the results should be reported soon. Similarly, there is a strong preclinical rationale for targeting TNF-related apoptosis-inducing ligand (TRAIL) death receptors. Nevertheless, results from a phase II study of mapatumumab, a human antibody against TRAIL death receptor R1 (TRAIL-R1), in patients with relapsed non-Hodgkin lymphoma were also disappointing, with a response rate of $12 \%$ in patients with relapsed indolent lymphoma. ${ }^{22}$ Why these mAbs targeting CD40 and TRAIL death receptors produced inferior results to those obtained with the empirical approach of using anti-CD20 antibodies remains unclear (Table 1). Several hypo-theses include a low expression of the death receptors, internalization of CD40, and a lack of complete blocking properties of dacetuzumab. These antibodies modulate functional receptors and, therefore, may have greater therapeutic value when used in combination regimens than as single agents. For example, in a pre clinical study, promising results have been observed when combining TRAIL death receptor agonistic antibodies with agents that downregulate pro-survival proteins or upregulate the expression of TRAIL death receptors. ${ }^{23}$ Whether combining these marginally active anti bodies with other active agents will be clinically beneficial remains to be seen. 
CD30 is a TNF superfamily transmembrane receptor and is highly expressed in patients with non-Hodgkin lymphoma and anaplastic large-cell lymphoma. CD30 is internalized, making it a suitable target for ADC strategies. Initial phase I and II clinical trials using firstgeneration naked anti-CD30 antibodies, such as SGN-35, were disappointing, especially in patients with relapsed Hodgkin lymphoma (Table 2). ${ }^{24,25}$ These poor results may be due to poor antigen binding properties, ineffective activation of effector cells, and neutralization by soluble CD30. Preliminary results from an ongoing phase I study of XmAb2513-derived from a humanized potent, chimeric anti-CD30 antibody, cAC10 (SGN-30)—suggest that this novel antibody may be more effective than the first-generation anti-CD30 antibodies. ${ }^{26}$

\section{Antibody-drug conjugates}

An ADC requires selective targeting of a cell surface antigen or receptor that can internalize to deliver the toxic drug inside the cell. CD22, C19, and CD30 are currently being targeted using this strategy with a variety of ADCs (Table 1). For example, CD22 is currently being targeted using ADCs that deliver Pseudomonas (BL22) or calicheamicin (inotuzumab ozogamicin). BL22 has an antibody-derived domain that recognizes CD22 and has a truncated Pseudomonas exotoxin domain that allows it to inhibit protein synthesis. BL22 has demonstrated clinical efficacy in patients with hairy-cell leukemia and is currently being evaluated in patients with CLL. ${ }^{27}$

Inotuzumab ozogamicin (CMC-544) is a humanized anti-CD22 antibody conjugated to calicheamicin, a potent antitumor antibiotic that binds to DNA. In a phase I study, inotuzumab ozogamicin was administered intravenously every 4 weeks in patients with relapsed B-cell lymphoma. ${ }^{28}$ The maximum tolerated dose was $1.8 \mathrm{mg} / \mathrm{m}^{2}$ and the doselimiting toxic effects (DLTs) were thrombocytopenia, neutropenia, and hepatic toxicity. Compared with epratuzumab, inotuzumab ozogamicin demonstrated an improved singleagent activity, with ORRs of $68 \%$ in follicular lymphoma and $15 \%$ in DLBCL (Table 1). ${ }^{28}$ In a follow-up study, inotuzumab ozogamicin was combined with rituximab in patients with relapsed follicular lymphoma or DLBCL. ${ }^{29}$ This novel antibody combination produced an ORR of $84 \%$ in 38 patients with follicular lymphoma, with a median progression-free survival (PFS) of 23.6 months. Patients with DLBCL $(n=40)$ had an ORR of $80 \%$, with a median PFS of 15.1 months. The ORR was only $20 \%$ in 25 patients with rituximabrefractory lymphoma, which was associated with a short median PFS (2 months).

SAR3419 is a humanized IgG1 mAb to CD19 that is conjugated to the maytansinoid derivative DM4, a potent tubulin inhibitor that binds to the vinca site. Results from a phase I study of SAR3419 in patients with relapsed CD19+ B-cell non-Hodgkin lymphoma showed this drug had no substantial hepatic or hematopoietic toxic effects. ${ }^{30}$ By contrast, the DLT of SAR3419 was reversible severe blurred vision, which was associated with microcystic epithelial corneal changes. OF 25 evaluable patients, 17 (68\%) demonstrated reduction in their tumor measurements, and of those patients, two achieved a partial response and three achieved a complete response. Furthermore, seven (53\%) of 13 patients with rituximabrefractory disease had a reduction in their tumor measurements. ${ }^{30}$ Thus, the lack of profound hematologic toxic effects and the ability to induce responses in rituximab- refractory patients may provide an opportunity for combining SAR3419 with other active regimens for the treatment of B-cell lymphoma. Although preclinical data have demonstrated the superiority of SAR3419 compared with the CD19 antibody, ${ }^{31}$ no comparative clinical data are available for patients with relapsed lymphoma using an anti-CD19 antibody. Thus, the exact contribution of DM4 to the activity of the naked antibody in patients with relapsed lymphoma remains undetermined. 
Brentuximab vedotin (SGN-35) is an ADC that conjugates the anti-CD30 antibody cAC10 (SGN-30) to monomethyl auristatin E, a synthetic antimicrotubule agent. ${ }^{32}$ In 2008, brentuximab vedotin was recently evaluated in two phase I clinical trials using different treatment schedules. In the first study, 45 patients with relapsed Hodgkin lymphoma and anaplastic large-cell lymphoma were treated with escalating doses of brentuximab vedotin $(0.1 \mathrm{mg} / \mathrm{kg}$ to $3.6 \mathrm{mg} / \mathrm{kg})$ by intravenous infusions every 3 weeks. The treatment was reasonably well tolerated; DLTs were neutropenia and hyperglycemia. Importantly, $88 \%$ of the patients demonstrated tumor reductions, and $40 \%$ achieved partial response or complete response (Table 2) ${ }^{33}$ In a second phase I study, 37 patients were treated with brentuximab vedotin that was administered weekly for 3 weeks in 4-week cycles. DLTs included grade 3 gastrointestinal toxic effects and grade 4 hyperglycemia. The ORR in 35 evaluable patients was $46 \%$. These results are remarkable especially when compared with those of the naked antibody SGN-30, which demonstrated no clinical activity in patients with relapsed Hodgkin lymphoma. On the basis of these encouraging results, a pivotal phase II trial recently completed enrollment of 104 patients treated with $1.8 \mathrm{mg} / \mathrm{kg}$ of brentuximab vedotin administered every 3 weeks. ${ }^{34}$

\section{Molecules targeting oncogenic pathways}

Advances in tumor biology have led to the identification of a variety of intracellular oncogenic pathways as potential targets for cancer therapy. These pathways can be targeted with small molecules that can selectively inhibit specific signaling molecules known to be activated in lymphoma, many of which are not 'driver' targets but contribute to the survival of lymphoma cells (Figure 1).

\section{The PI3K/Akt/mTOR pathway}

The PI3K/Akt/mTOR signaling pathway is dysfunctional in cancer, making it an important target for drug develop ment. ${ }^{35,36}$ Oncogenic activation of the PI3K pathway way is associated with gain-of-function mutations in the PI3K p110 $\alpha$ or $\mathrm{p} 85 \alpha$ isoforms and/or with the loss-of-function of PTEN (Figure 2). ${ }^{37-39}$ In lymphoid malignancies, PI3K pathway activation is rarely associated with these mutations; rather, it is linked to constitutive B-cell receptor activation and/or to exposure to survival factors present in the microenvironment, such as CD30, CD40, BAFF, and RANK. ${ }^{40-45}$

First-generation mTOR inhibitors were soluble rapamycin derivatives (rapalogs), two of which have been approved by the FDA for the treatment of renal-cell carcinoma: temsirolimus and everolimus. A third rapalog, ridaforolimus, is being tested in phase III trials (clinicaltrials.gov NCT00538239). the rapalogs work by binding to an adaptor protein FK506 binding protein 12 (FKBP12), preferentially inhibiting the formation of the downstream complex mTORC1, with no effect on mTORC2 ${ }^{46,47}$ More recently, smallmolecule inhibitors that compete with the ATP binding site in the mTOR kinase domain have entered clinical trials. These second-generation mTOR inhibitors inhibit both mTORC1 and $\mathrm{mTORC} 2$ and have demon strated in vitro activity in rapamycin-resistant cancer cell lines (Figure 2) ${ }^{47}$ The exact anticancer mechanisms of mTOR inhibitors remain unclear, but likely mechanisms include induction of autophagy, anti- angiogenesis, immunoregulation, and inhibition of protein trans lation of critical cell survival proteins. ${ }^{48-50}$ Thus, because mTOR inhibitors primarily induce cell-cycle arrest and autophagy, it is likely that clinical responses to mTOR inhibitors are augmented in vivo by modulation of the microenvironment and angiogenesis. ${ }^{51-53}$

Temsirolimus demonstrated broad activity in a variety of lymphoma subtypes (Table 3). ${ }^{54} \mathrm{~A}$ phase II trial of single-agent temsirolimus in patients with relapsed MCL reported an ORR of 38\% (13 of 34 patients); one patient achieved complete response, and 12 achieved a 
partial response. ${ }^{55}$ The most common adverse events were thrombocytopenia, anemia, neutropenia, hyperglycemia, increased triglycerides, mucositis, and fatigue. These encouraging results were not confirmed in a multicenter phase III trial that compared temsirolimus with commercially available chemotherapy drugs in patients with relapsed MCL. ${ }^{56}$ Although temsirolimus demonstrated improved PFS and improved ORR (22\% versus $2 \%$ ), the ORR was lower than what has been reported in smaller, single-institution phase II studies. Moreover, temsirolimus demonstrated promising clinical activity with an ORR of 56\% in patients with relapsed follicular lymphoma, 35\% for DLBCL, and $10 \%$ for small lymphocytic lymphoma (SLL, Table 3). ${ }^{54}$ Everolimus also has promising single-agent clinical activity in a variety of lymphoma subtypes, producing an ORR of 50\% in follicular lymphoma, 30\% in DLBCL, 18\% in SLL, 63\% in peripheral T-cell lymphoma, and 53\% in Hodgkin lymphoma (Table 3).

The strategy of targeting molecules upstream of mTOR, such as Akt and PI3K, is more potent than the use of mTOR inhibitors in vitro (as more downstream targets are inhibited); however, concerns about potential toxic effects of these agents has delayed their clinical development. ${ }^{37}$ An improved understanding of the PI3K signaling pathway has led to the identification of PI3K isoform targets. ${ }^{35,57}$ Three different PI3K classes have been identified, but only class I has been linked with oncogenesis. ${ }^{58}$ CAL-101 is a potent oral selective inhibitor of the PI3K isoform p110 . In human lymphoma cell lines, $\mathrm{p} 110 \delta$ expression was observed in $>90 \%$ of cases and was frequently associated with constitutive phosphorylation of Akt. CAL-101 decreased levels of phosphorylated Akt and other downstream effectors, such as S6 kinase and GSK-3 $\beta$, resulting in inhibition of growth and induction of apoptosis in a variety of lymphoma cell lines. ${ }^{59}$ In a phase I study in patients with lymphoid malignancies, CAL-101 was administered at increasing doses (50 mg to 350 $\mathrm{mg}$ ) orally twice daily in 28-day cycles. Although no hematologic DLTs were observed, serious hepatic toxic effects and infections were reported. Remarkably, $10(56 \%)$ of 18 patients achieved a partial response (five with indolent lymphoma and five with MCL) ${ }^{60}$ These data, together with results achieved using mTOR inhibitors, confirm that targeting the $\mathrm{PI} 3 \mathrm{~K} / \mathrm{Akt} / \mathrm{mTOR}$ pathway is a promising strategy for the treatment of lymphoma.

\section{Proteasome inhibition}

The proteasome regulates cellular protein homeostasis. Inhibition of the proteasome function alters the cellular content of a variety of cell cycle and survival proteins, leading to cellcycle arrest and apoptosis. The first proteasome inhibitor to be approved by the FDA was bortezomib, a potent, selective, and reversible inhibitor of the $26 \mathrm{~S}$ proteasome. In relapsed and/or refractory MCL, the ORR with bortezomib was 39-54\%. ${ }^{61}$ Bortezomib demonstrated modest activity in other types of lymphoma and had no activity in patients with relapsed Hodgkin lymphoma. ${ }^{62,63}$ Bortezomib may have a role in enhancing the efficacy of conventional chemotherapy by modulating intracellular resistance factors, such as nuclear factor-kappa B (NF-kB). This hypothesis is currently being tested in prospective clinical trials combining bortezomib with a variety of chemotherapy regimens, including R-CHOP.

In a study that examined the efficacy of bortezomib plus rituximab and EPOCH chemotherapy in patients with DLBCL, the greatest benefit was observed in a subset of patients with the activated $\mathrm{B}$ cell, which has been shown to be associated with constitutive activation of the NF- $\mathrm{KB}$ pathway. ${ }^{64}$ Bortezomib is also being combined with other biological agents, including mAbs and histone deacetylase (HDAC) inhibitors. In an alternative approach, several companies are currently develop ing second-generation proteasome inhibitors aimed at improved clinical activity and reduced toxic effects, which could allow these agents to be combined with chemotherapy. 


\section{Histone deacetylases}

HDACs are promising targets because they inhibit several oncogenic pathways and have a role in regulating cell-cycle progression, survival, angiogenesis, and immunity. ${ }^{65}$ The 18 human HDACs currently known are grouped into four classes: class I (HDACs 1, 2, 3, and 8), class II (HDACs 4, 5, 6, 7, 9, and 10), class III sirtuins (SIRT1 to SIRT7), and class IV (HDAC 11, Supplementary Figure 1). Small-molecule HDAC inhibitors are broadly classified as pan-HDAC inhibitors (vorinostat, romidepsin, and panobinostat) or class I HDAC inhibitors (mocetinostat and entinostat). Two HDAC inhibitors, vorinostat and romidepsin, have been approved by the FDA for the treatment of cutaneous T-cell lymphoma (CTCL). ${ }^{66,67}$ Vorinostat produced an ORR of $30 \%$ in 74 patients with relapsed CTCL. ${ }^{66}$ Similarly, romidepsin produced an ORR of $34 \%$ in 71 patients with relapsed CTCL. ${ }^{67}$ In both studies, fatigue and thrombocytopenia were frequently observed. In another study, romidepsin demonstrated a $33 \%$ response rate in heavily pretreated patients with relapsed peripheral T-cell lymphoma. ${ }^{68}$

HDAC inhibitors have promising clinical activity in patients with relapsed Hodgkin lymphoma. ${ }^{69}$ in a phase II study, mocetinostat (MGCD0103), a novel oral HDAC inhibitor that selectively inhibits the HDAC 1 and 2 isoforms, produced an ORR of $35 \%$ in heavily pretreated patients with relapsed Hodgkin lymphoma. ${ }^{70}$ The most common toxic effects were fatigue and gastrointestinal symptoms, which resulted in dose interruptions, dose reductions, and discontinuation of therapy. Results from clinical trials of vorinostat and panobinostat were reported in patients with relapsed Hodgkin lymphoma. ${ }^{71,72}$ The Southwest Oncology Group (SWOG) conducted a phase II trial of vorinostat. ${ }^{71}$ Of the 25 patients who were treated with vorinostat administered orally at $200 \mathrm{mg}$ twice daily for 14 days in 21-day cycles, only one patient achieved a partial response. Panobinostat was evaluated in phase I and II trials in patients with relapsed Hodgkin lymphoma. ${ }^{72}$ In the phase I study, five (38\%) of 13 patients achieved partial response. The most common toxic effects were fatigue, thrombocytopenia, nausea, and diarrhea. On the basis of this promising clinical activity, a multicenter, international phase II study of panobinostat in relapsed Hodgkin lymphoma was initiated, and preliminary results have demonstrated an ORR of approximately $20 \%$; thrombocytopenia was the most common grade $3 / 4$ toxic effect. ${ }^{73}$ The clinical activity of HDAC inhibitors in other types of lymphoma was more modest. Collectively, both class I HDAC inhibitors and pan-HDAC inhibitors have demonstrated clinical activity in patients with relapsed non-Hodgkin lymphoma and Hodgkin lymphoma. ${ }^{69}$ HDAC inhibitors have demonstrated promising single-agent activity in a variety of lymphoid malignancies, but because they modulate a variety of survival factors, the future use of these compounds will be in combination with other active agents. Several HDAC inhibitor-based regimens are currently being examined in various stages of clinical trials, including combinations with hypo methylating agents, rituximab, proteasome inhibitors, and chemotherapy.

\section{Immunomodulatory drugs}

Lenalidomide is a derivative of thalidomide and is an immunomodulatory agent. The mechanism of action is not completely understood, but it involves a direct antiproliferative effect, modulation of the tumor microenvironment, inhibition of angiogenesis, and enhancement of immune cell function. Several phase II studies have demonstrated promising clinical activity of lenalidomide in a variety of lymphoma subtypes when administered orally at $25 \mathrm{mg}$ daily for 3 weeks in 4 -week cycles. ${ }^{74,75}$ The ORRs were $27 \%$, $28 \%, 42 \%$, and $45 \%$, respectively, in patients with relapsed follicular lymphoma, DLBCL, MCL, and TCL (Table 3). Importantly, responses were seen in patients who had failed to respond to their previous regimen, including rituximab-refractory patients. Lenalidomide also demonstrated modest clinical activity in patients with relapsed Hodgkin lymphoma, 
with an ORR of $18 \%{ }^{76,77}$ In these studies, the primary toxic effect was myelosuppression, which required dose reductions or interruptions in almost $50 \%$ of patients. This toxicity profile suggests that combining lenalidomide with conventional chemotherapy regimens might be difficult and that alternative approaches should be investigated, including administration of lenalidomide as maintenance after chemotherapy or in combination with other biologic agents that have minimal hematologic toxic effects, such as rituximab. ${ }^{78,79}$

\section{Other promising agents in development}

\section{BCR signaling}

In subsets of B-cell lymphomas, augmented BCR signaling may promote their survival, ${ }^{80}$ which led to the develop ment of small molecules that inhibit Syk and Bruton's tyrosine kinase (involved in B-cell receptor signaling) ${ }^{80-82}$ In a phase II study, fostamatinib, a Syk small-molecule inhibitor, demonstrated clinical activity in a variety of B-cell malignancies; the highest ORR, 55\%, was observed in patients with relapsed SLL or CLL (Table 3). ${ }^{81}$ Similarly, a phase I study of the Bruton's tyrosine kinase small-molecule inhibitor PCI32765 demonstrated clinical activity in a variety of B-cell lymphoid malignancies. ${ }^{82}$

\section{Targeting apoptosis machinery}

In addition to mAbs that target the TRAIL death receptors, small molecules are currently being developed to target members of the Bcl-2 family and the inhibitors of apoptosis family. ${ }^{83-86}$ These small molecules were developed based on a detailed understanding of the intrinsic and extrinsic death pathways. ${ }^{87}$ Most of these agents have failed to produce substantial single-agent activity in patients with relapsed lymphoma. For example, in a phase II study of the anti-survivin compound YM155, only one of the 35 evaluable patients with relapsed DLBCL responded. ${ }^{83}$ Similarly, the novel oral anti-Bcl-2 inhibitor ABT-263 produced an ORR of $11 \%$ in 27 patients with relapsed SLL or CLL and a much lower ORR in other types of B-cell lymphomas. ${ }^{85}$ These results are somewhat disappointing, given the well-established role of the Bcl-2 family in survival of lymphoma cells. These critical survival protein-modulating drugs may be better suited for combination strategies with chemo therapy or other targeted agents. Furthermore, these studies illustrate the need to identify predictive biomarkers in order to enrich the populations that are likely to benefit from these novel targeted agents.

\section{JAK and STAT pathway}

The Janus kinase (JAK) and signal transducer and activator of transcription (STAT) pathway has an important role in the proliferation and pathogenesis of hematologic malignancies. Somatic activating point mutations in JAK2 have been reported in most myeloproliferative dis orders but are rarely described in Hodgkin lymphoma and nonHodgkin lymphoma. ${ }^{88,89} \mathrm{JAK} 2$ activation has been associated with mutation of the suppressor of cytokine signaling-1 gene in Hodgkin lymphoma and primary mediastinal large B-cell lymphoma. ${ }^{90,91}$ Activated STAT3 and STAT5 signaling promotes the growth and survival of a variety of lymphomas; ${ }^{92-100}$ thus, in a phase I study, the novel oral JAK2 small-molecule inhibitor SB1518 was evaluated in patients with relapsed Hodgkin lymphoma and non-Hodgkin lymphoma. ${ }^{101}$ Clinical responses were observed in patients with relapsed MCL, follicular lymphoma, SLL, and Hodgkin lymphoma. A phase II clinical trial is expected to enroll patients in 2010 to confirm this promising clinical activity.

\section{Challenges and future directions}

As more molecular targets are identified, the number of new targeted anticancer agents continues to increase- more than 800 such compounds are currently in active clinical 
development. ${ }^{102}$ However, because of tumor heterogeneity and the complex interplay between several oncogenic pathways in lymphoma, it is not surprising that the ORRs of targeted drugs in unselected lymphoma patients rarely exceed $30 \%$ (Figure 3 ).

\section{Design of clinical trials}

There is a need to develop a more efficient way to evaluate new agents, especially in phase I studies. Poorly designed studies not only waste resources but may also lead to premature decisions to halt the development of potentially effective agents. Despite the importance of phase I studies in the development of oncology drugs, their value is frequently shadowed by the fact that they are traditionally offered to patients with advanced-stage tumors who have no other therapeutic option. In a different approach, phase I novel agents could be evaluated in less heavily pretreated patients with certain types of chronic, non-life threatening but incurable lymphomas; such trials could provide valuable information on the agents' safety and potential efficacy.

Although the goal of phase I chemotherapeutic studies is to establish the maximum tolerated dose and to recommend a dose for further testing in subsequent trials, this goal may not be ideal in the era of targeted therapy. Indeed, meaningful clinical responses are frequently observed at dose levels below the maximum tolerated dose, indicating a need to develop novel phase I designs for targeted agents. ${ }^{103,104}$ As new agents are increasingly combined with conventional chemo therapy regimens and/or with other targeted agents, innovative phase I designs of combination regimens are also required to expedite their development. For example, combination studies should consider including several treatment arms, instead of the traditional but inefficient approach of using one combination per study. This novel design was recently adopted for the treatment of patients with locally advanced breast carcinoma. ${ }^{105}$ One study combined the anti-TRAIL-R $2 \mathrm{mAb}$ conatumumab with either vorinostat or bortezomib in patients with relapsed lymphoma, with reasonable DLTs and preliminary evidence of anti-tumor activity. ${ }^{106}$

\section{Timely enrollment in clinical trials}

Approximately $3 \%$ of cancer patients usually participate in clinical trials; given that about 74,000 patients were diagnosed as having lymphoma in the USA in 2009 , an estimated 2,200 patients with lymphoma were probably enrolled in clinical trials in 2009 (an average of nine patients per clinical trial per year). These numbers explain why many studies close prematurely because of lack of enrollment. There is an urgent need to prioritize our efforts and avoid activating new studies that answer marginal questions.

Randomized phase II trials that combine new targeted agents with standard regimens should be used more frequently, especially with adaptive randomization designs. Such designs may reduce the sample sizes and may encourage patients to participate because they are assured that they have a higher chance of being randomized to the more-effective regimen. As some of the new targeted drugs are incorporated into frontline regimens, it will be important to design clinical trials that can reach the primary end points in a timely manner. Currently, at least five large-scale randomized studies are enrolling newly diagnosed patients with advanced-stage DLBCL, and all use the same standard arm, R-CHOP. The experimental arm of these trials adds one investigational drug to R-CHOP, either concurrently (bortezomib and epratuzumab) or in a maintenance schedule (enzastaurin, everolimus, and lenalidomide). This inefficient, uncoordinated phase III study design should be modified in the future. A possible alternative would be a large multiarm randomized study with only one arm using the standard R-CHOP and other, simultaneous arms evaluate several new agents in combination with R-CHOP. Such an approach, which would require a major collaborative 
effort between pharmaceutical companies, the FDa, and academia, could expedite results from clinical trials.

\section{Predictive biomarkers and patient selection}

Despite the elegant scientific rationale for the development of molecular targeted agents, these novel drugs rarely produce a single-agent ORR that exceeds 30\% (Figure 3 ). This poor outcome may be related to the lack of proper patient selection. Therefore, the identification of predictive biomarkers should enable the selection of patients who are likely to have better ORRs to a certain therapy. Current data demonstrate that the mere expression of the therapeutic target is not sufficient to predict treatment response (Table 4) because many novel agents do not target 'driver' oncogenic defects. For example, although $100 \%$ of patients with relapsed indolent lymphoma enrolled in the clinical trial were required to have documented evidence of CD20 expression, only $50 \%$ of patients responded to the anti-CD20 mAb rituximab. ${ }^{9}$ Similarly, only $10 \%$ of patients with relapsed CD22 ${ }^{+}$DLBCL responded to the anti-CD22 mAb epratuzumab. Thus, although the expression of the molecular target is required, it is not sufficient to predict response to the targeted agent. Therefore, identifying predictive bio-markers that are independent of the therapeutic target is important.

The failure to link several molecular targets to treatment outcome is likely due to the fact that many of these targets are not involved in the oncogenic process; examples are CD20 and CD22 expression. By contrast, the presence of targets that relate to oncogenesis can predict treatment outcome and such targets have been proposed as a criterion for patient selection. This concept is easy to understand when the targeted drug inhibits only one target, with no off-target effects, but it becomes more complex when the targeted agent has several, sometimes favorable, off-target effects. Thus, these off-target effects should be considered when future predictive biomarkers are evaluated.

In the era of targeted therapy, early phase I and II clinical trials of novel agents should always incorporate translational studies to identify potential biomarkers that can be validated in subsequent studies. Empirical studies with only clinical end points should be avoided, despite being cheaper to conduct. For example, although pre-clinical experiments and results from a phase I study suggested that patients with DLBCL were likely to respond to YM155 (a small-molecule inhibitor of survivin), the drug produced an ORR of only 3\% in a phase II study. ${ }^{83,107}$ Unfortunately, because the trial neither evaluated nor required the presence of survivin expression in patients' tumors, drawing any conclusions from that study is difficult. Moreover, the study did not incorporate translational studies on patients' biospecimens to determine whether the doses of YM155 inhibited survivin in vivo. Thus, these types of empirical designs for trials of novel targeted drugs should be avoided because they rarely advance the field. By contrast, when 'driver' oncogenic defects are identified and used to preselect patients for specific drugs, these trials have a higher chance of producing clinical responses. Successful examples include the presence of BCR-ABL in certain types of leukemia, EGFR mutations in non-small-cell lung carcinoma, ${ }^{108} B R A F$ mutations in melanoma, ${ }^{109}$ and wild-type, non-mutated KRAS in colorectal carcinoma. ${ }^{110}$ No such 'driver' molecular biomarkers have been identified for lymphoma patients, and the search for these biomarkers should continue to be a high priority.

\section{Lymphoma response criteria}

The clinical end points of studies of single-agent targeted drugs rely heavily on ORR and PFS to identify promising agents for further clinical development. Therefore, the definitions of disease progression and disease response should be modified to provide a more accurate and uniform interpretation of clinical trials. Furthermore, many phase I studies include patients with both solid tumors and lymphoma and use RECIST in the trial design. ${ }^{111} \mathrm{By}$ 
contrast, lymphoma-specific studies use the revised response criteria, which differ from RECIST in several important aspects, including the definition of response and how to measure it. ${ }^{112}$ Although the current revised response criteria for malignant lymphoma are suitable for assessing tumor response and PFS achieved with frontline regimens, they lack important details needed to accurately evaluate response to single-agent drugs in the relapsed setting. For example, the current system does not address how to measure a large mass that becomes several smaller masses during a response, nor does it address the appearance of a PET-positive small extra nodal lesion in a setting of a disease response. Moreover, some of the targeted agents may alter inflammatory cytokines in the tumor microenvironment or glucose uptake in the tumor cells, thereby inducing a false positive or false negative result in PET analysis. These changes may influence imaging results that may be incorrectly interpreted as disease response or disease progression. Future revisions in the response criteria should take these deficiencies into account and should include new assessment methods, such as molecular imaging.

\section{Conclusions}

As more targeted agents are developed for cancer therapy, prioritizing clinical trials with these novel agents is important to ensure that patients are enrolled in a timely manner. Furthermore, because most of these agents are expected to produce modest ORRs in unselected patients, correlative studies should be performed on biospecimens obtained from patients enrolled in these trials to identify molecular biomarkers for treatment response. Most tumors are expected to activate more than one oncogenic pathway, so rationally designed trials should be initiated to combine multiple targeted agents. Eventually, various combination regimens will be selected by using predictive biomarkers from individual patients, as has been proposed for patients with breast cancer and melanoma. ${ }^{105,113}$ This personalized treatment approach will improve the cure rate while reducing treatment- related toxic effects.

\section{Supplementary Material}

Refer to Web version on PubMed Central for supplementary material.

\section{Acknowledgments}

This work is partially supported by lymphoma SPORE grant 1P50CA136411-01A1, Clay Chiles Lymphoma Fund, Jack L. Stotsky Memorial Fund, and the Living Legend Fund.

\section{References}

1. Jemal A, Center MM, Ward E, Thun MJ. Cancer occurrence. Methods Mol. Biol. 2009; 471:3-29. [PubMed: 19109772]

2. Zelenetz AD, et al. NCCN Clinical Practice Guidelines in Oncology: non-Hodgkin's Lymphomas. J. Natl Compr. Canc. Netw. 2010; 8:288-334. [PubMed: 20202462]

3. Sridhara R, et al. Review of oncology and hematology drug product approvals at the US Food and Drug Administration between July 2005 and December 2007. J. Natl Cancer Inst. 2010; 102:230 243. [PubMed: 20118413]

4. Cheson BD, Leonard JP. Monoclonal antibody therapy for B-cell non-Hodgkin's lymphoma. N. Engl. J. Med. 2008; 359:613-626. [PubMed: 18687642]

5. Coiffier B, et al. Safety and efficacy of ofatumumab, a fully human monoclonal anti-CD20 antibody, in patients with relapsed or refractory B-cell chronic lymphocytic leukemia: a phase 1-2 study. Blood. 2008; 111:1094-1100. [PubMed: 18003886] 
6. Coiffier B, et al. CHOP chemotherapy plus rituximab compared with CHOP alone in elderly patients with diffuse large-B-cell lymphoma. N. Engl. J. Med. 2002; 346:235-242. [PubMed: 11807147]

7. Hagenbeek A, et al. First clinical use of ofatumumab, a novel fully human anti-CD20 monoclonal antibody in relapsed or refractory follicular lymphoma: results of a phase 1/2 trial. Blood. 2008; 111:5486-5495. [PubMed: 18390837]

8. Hagenbeek A, et al. Evaluation of ofatumumab, a novel human CD20 monoclonal antibody, as single agent therapy in rituximab-refractory follicular lymphoma. Blood (ASH Annual Meeting Abstracts). 2009; 114:935.

9. McLaughlin P, et al. Rituximab chimeric anti-CD20 monoclonal antibody therapy for relapsed indolent lymphoma: half of patients respond to a four-dose treatment program. J. Clin. Oncol. 1998; 16:2825-2833. [PubMed: 9704735]

10. Maloney DG. Rituximab for follicular lymphoma. Curr. Hematol. Rep. 2003; 2:13-22. [PubMed: 12901150]

11. Leonard JP, et al. Phase I/II trial of epratuzumab (humanized anti-CD22 antibody) in indolent nonHodgkin's lymphoma. J. Clin. Oncol. 2003; 21:3051-3059. [PubMed: 12837807]

12. Byrd JC, et al. Phase 1 study of lumiliximab with detailed pharmacokinetic and pharmacodynamic measurements in patients with relapsed or refractory chronic lymphocytic leukemia. Clin. Cancer Res. 2007; 13:4448-4455. [PubMed: 17671129]

13. Bargou R, et al. Tumor regression in cancer patients by very low doses of a $\mathrm{T}$ cell-engaging antibody. Science. 2008; 321:974-977. [PubMed: 18703743]

14. Baeuerle PA, Reinhardt C. Bispecific T-cell engaging antibodies for cancer therapy. Cancer Res. 2009; 69:4941-4944. [PubMed: 19509221]

15. Nagorsen D, et al. Confirmation of safety, efficacy and response duration in non-Hodgkin lymphoma patients treated with $60 \mu \mathrm{g} / \mathrm{m}^{2} / \mathrm{d}$ of BiTE(R) antibody blinatumomab. Blood (ASH Annual Meeting Abstracts). 2009; 114:2723.

16. Topp MS, et al. Report of a phase ii trial of single-agent BiTE(R) antibody blinatumomab in patients with minimal residual disease (MRD) positive B-precursor acute lymphoblastic leukemia (ALL). Blood (ASH Annual Meeting Abstracts). 2009; 114:840.

17. Strauss SJ, et al. Multicenter phase II trial of immunotherapy with the humanized anti-CD22 antibody, epratuzumab, in combination with rituximab, in refractory or recurrent non-Hodgkin's lymphoma. J. Clin. Oncol. 2006; 24:3880-3886. [PubMed: 16864854]

18. Micallef IN, et al. Final results of NCCTG N0489: Epratuzumab and rituximab in combination with cyclophosphamide, doxorubicin, vincristine, and prednisone chemotherapy (ER-CHOP) in patients with previously untreated diffuse large B-cell lymphoma. J. Clin. Oncol. ASCO Meeting Abstracts. 2009; 27(Suppl.):8508.

19. Younes A, Kadin ME. Emerging applications of the tumor necrosis factor family of ligands and receptors in cancer therapy. J. Clin. Oncol. 2003; 21:3526-3534. [PubMed: 12972530]

20. Advani R, et al. A phase 2 clinical trial of SGN-40 monotherapy in relapsed diffuse large B-cell lymphoma. Blood (ASH Annual Meeting Abstracts). 2008; 112:1000.

21. Advani R, et al. Phase I study of the humanized anti-CD40 monoclonal antibody dacetuzumab in refractory or recurrent non-Hodgkin's lymphoma. J. Clin. Oncol. 2009; 27:4371-4377. [PubMed: 19636010]

22. Younes A, et al. Results of a phase 2 trial of HGS-ETR1 (agonistic human monoclonal antibody to TRAIL receptor 1) in subjects with relapsed/refractory non-Hodgkin's lymphoma (NHL) (ETR1-01). Blood (ASH Annual Meeting Abstracts). 2005; 106:489.

23. Wang S. The promise of cancer therapeutics targeting the TNF-related apoptosis-inducing ligand and TRAIL receptor pathway. Oncogene. 2008; 27:6207-6215. [PubMed: 18931688]

24. Bartlett NL, et al. A phase 1 multidose study of SGN-30 immunotherapy in patients with refractory or recurrent CD30+ hematologic malignancies. Blood. 2008; 111:1848-1854. [PubMed: 18079362]

25. Ansell SM, et al. Phase I/II study of an anti-CD30 monoclonal antibody (MDX-060) in Hodgkin's lymphoma and anaplastic large-cell lymphoma. J. Clin. Oncol. 2007; 25:2764-2769. [PubMed: 17515574] 
26. Blum KA, et al. Phase I study of an anti-CD30 Fc engineered humanized monoclonal antibody in Hodgkin lymphoma (HL) or anaplastic large cell lymphoma (ALCL) patients: Safety, pharmacokinetics (PK), immunogenicity, and efficacy. J. Clin. Oncol. ASCO Meeting Abstracts. 2009; 27(Suppl.):8531.

27. Kreitman RJ, et al. Phase I trial of recombinant immunotoxin RFB4(dsFv)-Pe38 (BL22) in patients with B-cell malignancies. J. Clin. Oncol. 2005; 23:6719-6729. [PubMed: 16061911]

28. Advani A, et al. Safety, pharmacokinetics, and preliminary clinical activity of inotuzumab ozogamicin, a novel immunoconjugate for the treatment of B-cell non-Hodgkin's lymphoma: results of a phase I study. J. Clin. Oncol. 2010; 28:2085-2093. [PubMed: 20308665]

29. Dang NH, et al. Anti-CD22 immunoconjugate inotuzumab ozogamicin (CMC-544) + rituximab: clinical activity including survival in patients with recurrent/refractory follicular or 'aggressive' lymphoma. Blood (ASH Annual Meeting Abstracts). 2009; 114:584.

30. Younes A, et al. Phase I multi-dose escalation study of the anti-CD19 maytansinoid immunoconjugate SAR3419 administered by intravenous (IV) infusion every 3 weeks to patients with relapsed/ refractory B-cell non-hodgkin's lymphoma (NHL). Blood (ASH Annual Meeting Abstracts). 2009; 114:585.

31. Aboukameel A, et al. Superior anti-tumor activity of the CD19-directed immunotoxin, SAR3419 to rituximab in non-Hodgkin's xenograft animal models: preclinical evaluation. Blood (ASH Annual Meeting Abstracts). 2007; 110:2339.

32. Oflazoglu E, Kissler KM, Sievers EL, Grewal IS, Gerber HP. Combination of the anti-CD30auristatin-e antibody-drug conjugate (SGN-35) with chemotherapy improves antitumour activity in Hodgkin lymphoma. Br. J. Haematol. 2008; 142:69-73. [PubMed: 18477046]

33. Younes A, et al. Multiple complete responses in a phase 1 dose-escalation study of the antibodydrug conjugate SGN-35 in patients with relapsed or refractory CD30-positive lymphomas. Blood (ASH Annual Meeting Abstracts). 2008; 112:1006.

34. Fanale M, et al. The antibody-drug conjugate brentuximab vedotin (SGN-35) induced multiple objective responses in patients with relapsed or refractory CD30-positive lymphomas in a phase 1 weekly dosing study. Blood (ASH Annual Meeting Abstracts). 2009; 114:2731.

35. Ihle NT, Powis G. Take your PIK: phosphatidylinositol 3-kinase inhibitors race through the clinic and toward cancer therapy. Mol. Cancer Ther. 2009; 8:1-9. [PubMed: 19139107]

36. Franke TF. PI3K/Akt: getting it right matters. Oncogene. 2008; 27:6473-6488. [PubMed: 18955974]

37. Engelman JA. Targeting PI3K signalling in cancer: opportunities, challenges and limitations. Nat. Rev. Cancer. 2009; 9:550-562. [PubMed: 19629070]

38. Jaiswal BS, et al. Somatic mutations in p85alpha promote tumorigenesis through class IA PI3K activation. Cancer Cell. 2009; 16:463-474. [PubMed: 19962665]

39. Berenjeno IM, Vanhaesebroeck B. PI3K regulatory subunits lose control in cancer. Cancer Cell. 2009; 16:449-450. [PubMed: 19962660]

40. Georgakis GV, Yazbeck VY, Li Y, Younes A. Preclinical rationale for therapeutic targeting of mTOR by CC-I779 and rapamycin in Hodgkin lymphoma. J. Clin. Oncol. ASCO Meeting Abstracts. 2006; 24(Suppl.):10070.

41. Jücker M, et al. Expression of a mutated form of the p85alpha regulatory subunit of phosphatidylinositol 3-kinase in a Hodgkin's lymphoma-derived cell line (CO). Leukemia. 2002; 16:894-901. [PubMed: 11986952]

42. Morrison JA, Gulley ML, Pathmanathan R, Raab-Traub N. Differential signaling pathways are activated in the epstein-Barr virus-associated malignancies nasopharyngeal carcinoma and Hodgkin lymphoma. Cancer Res. 2004; 64:5251-5260. [PubMed: 15289331]

43. Nagel S, et al. HLXB9 activates IL6 in Hodgkin lymphoma cell lines and is regulated by PI3K signalling involving E2F3. Leukemia. 2005; 19:841-846. [PubMed: 15772702]

44. Renné C, et al. High expression of several tyrosine kinases and activation of the PI3K/AKT pathway in mediastinal large B cell lymphoma reveals further similarities to Hodgkin lymphoma. Leukemia. 2007; 21:780-787. [PubMed: 17375124] 
45. Dutton A, Reynolds GM, Dawson CW, Young LS, Murray PG. Constitutive activation of phosphatidyl-inositide 3 kinase contributes to the survival of Hodgkin's lymphoma cells through a mechanism involving Akt kinase and mTOR. J. Pathol. 2005; 205:498-506. [PubMed: 15714459]

46. Gough NR. Focus Issue: demystifying mTOR signaling. Sci. Signal. 2009; 2:eg5. [PubMed: 19383973]

47. Dancey J. mTOR signaling and drug development in cancer. Nat. Rev. Clin. Oncol. 2010; 7:209219. [PubMed: 20234352]

48. Thomson AW, Turnquist HR, Raimondi G. Immunoregulatory functions of mTOR inhibition. Nat. Rev. Immunol. 2009; 9:324-337. [PubMed: 19390566]

49. Ma XM, Blenis J. Molecular mechanisms of mTOR-mediated translational control. Nat. Rev. Mol. Cell Biol. 2009; 10:307-318. [PubMed: 19339977]

50. Younes A. Therapeutic activity of mTOR inhibitors in mantle cell lymphoma: clues but no clear answers. Autophagy. 2008; 4:707-709. [PubMed: 18469512]

51. Zheng Y, et al. A role for mammalian target of rapamycin in regulating $\mathrm{T}$ cell activation versus anergy. J. Immunol. 2007; 178:2163-2170. [PubMed: 17277121]

52. Del Bufalo D, et al. Antiangiogenic potential of the mammalian target of rapamycin inhibitor temsirolimus. Cancer Res. 2006; 66:5549-5554. [PubMed: 16740688]

53. Younes A. Therapeutic activity of mTOR inhibitors in mantle cell lymphoma: clues but no clear answers. Autophagy. 2008; 4:707-709. [PubMed: 18469512]

54. Smith SM, et al. Activity of single agent temsirolimus (CCi-779) in non-mantle cell non-Hodgkin lymphoma subtypes. J. Clin. Oncol. ASCO Meeting Abstracts. 2008; 26(Suppl.):8514.

55. Witzig TE, et al. Phase II trial of single-agent temsirolimus (CCi-779) for relapsed mantle cell lymphoma. J. Clin. Oncol. 2005; 23:5347-5356. [PubMed: 15983389]

56. Hess G, et al. Phase III study to evaluate temsirolimus compared with investigator's choice therapy for the treatment of relapsed or refractory mantle cell lymphoma. J. Clin. Oncol. 2009; 27:3822_ 3829. [PubMed: 19581539]

57. Courtney KD, Corcoran RB, Engelman JA. The PI3K pathway as drug target in human cancer. J. Clin. Oncol. 2010; 28:1075-1083. [PubMed: 20085938]

58. Zhao L, Vogt PK. Class I PI3K in oncogenic cellular transformation. Oncogene. 2008; 27:54865496. [PubMed: 18794883]

59. Lannutti BJ, et al. CAL-101, an oral p110\{delta\} selective phosphatidylinositol-3- kinase (PI3K) inhibitor for the treatment of B cell malignancies inhibits PI3K signaling, cellular viability and protective signals of the microenvironment. Blood (ASH Annual Meeting Abstracts). 2009; 114:286.

60. Flinn IW, et al. evidence of clinical activity in a phase 1 study of CAL-101, an oral P110\{delta\} isoform-selective inhibitor of phosphatidylinositol 3-kinase, in patients with relapsed or refractory B-cell malignancies. Blood (ASH Annual Meeting Abstracts). 2009; 114:922.

61. Fisher RI, et al. Multicenter phase ii study of bortezomib in patients with relapsed or refractory mantle cell lymphoma. J. Clin. Oncol. 2006; 24:4867-4874. [PubMed: 17001068]

62. Blum KA, et al. Single agent bortezomib in the treatment of relapsed and refractory Hodgkin lymphoma: cancer and leukemia Group B protocol 50206. Leuk. Lymphoma. 2007; 48:13131319. [PubMed: 17613759]

63. Younes A, Pro B, Fayad L. experience with bortezomib for the treatment of patients with relapsed classical Hodgkin lymphoma. Blood. 2006; 107:1731-1732. [PubMed: 16461762]

64. Dunleavy K, et al. Differential efficacy of bortezomib plus chemotherapy within molecular subtypes of diffuse large B-cell lymphoma. Blood. 2009; 113:6069-6076. [PubMed: 19380866]

65. Xu WS, Parmigiani RB, Marks PA. Histone deacetylase inhibitors: molecular mechanisms of action. Oncogene. 2007; 26:5541-5552. [PubMed: 17694093]

66. Duvic M, et al. Phase 2 trial of oral vorinostat (suberoylanilide hydroxamic acid, SAHA) for refractory cutaneous T-cell lymphoma (CTCL). Blood. 2007; 109:31-39. [PubMed: 16960145]

67. Piekarz RL, et al. Phase II multi-institutional trial of the histone deacetylase inhibitor romidepsin as monotherapy for patients with cutaneous T-cell lymphoma. J. Clin. Oncol. 2009; 27:54105417. [PubMed: 19826128] 
68. Piekarz R, et al. Final results of a phase $2 \mathrm{NCl}$ multicenter study of romidepsin in patients with relapsed peripheral T-cell lymphoma (PTCL). Blood (ASH Annual Meeting Abstracts). 2009; 114:1657.

69. Younes A. Novel treatment strategies for patients with relapsed classical Hodgkin lymphoma. Hematology Am. Soc. Hematol. Educ. Program. 2009:507-519. [PubMed: 20008236]

70. Younes A, et al. Isotype-selective HDAC inhibitor MGCD0103 decreases serum TARC concentrations and produces clinical responses in heavily pretreated patients with relapsed classical Hodgkin lymphoma (HL). Blood (ASH Annual Meeting Abstracts). 2007; 110:2566.

71. Kirschbaum MH, et al. Vorinostat (suberoylanilide hydroxamic acid) in relapsed or refractory Hodgkin lymphoma: SwOG 0517. Blood (ASH Annual Meeting Abstracts). 2007; 110:2574.

72. Spencer A, et al. Oral panobinostat (LBH589), a novel deacetylase inhibitor (DACi) demonstrates clinical activity in relapsed/refractory Hodgkin lymphoma (HL) [abstract]. Ann. Oncol. 2008; 19:a136.

73. Younes A, et al. Efficacy of panobinostat in phase II study in patients with relapsed/refractory Hodgkin lymphoma (HL) after high-dose chemotherapy with autologous stem cell transplant. Blood (ASH Annual Meeting Abstracts). 2009; 114:923.

74. Witzig TE, et al. Lenalidomide oral monotherapy produces durable responses in relapsed or refractory indolent non-Hodgkin's lymphoma. J. Clin. Oncol. 2009; 27:5404-5409. [PubMed: 19805688]

75. Witzig TE, et al. Durable responses after lenalidomide oral monotherapy in patients with relapsed or refractory (R/R) aggressive non-Hodgkin's lymphoma (a-NHL): results from an international phase 2 study (CC-5013-NHL-003). Blood (ASH Annual Meeting Abstracts). 2009; 114:1676.

76. Fehniger TA, et al. A phase II multicenter study of lenalidomide in relapsed or refractory classical Hodgkin lymphoma. Blood (ASH Annual Meeting Abstracts). 2009; 114:3693.

77. Kuruvilla J, et al. Phase II trial of lenalidomide in patients with relapsed or refractory Hodgkin lymphoma. Blood (ASH Annual Meeting Abstracts). 2008; 112:3052.

78. Fowler N, et al. A biologic combination of lenalidomide and rituximab for front-line therapy of indolent B-cell non-Hodgkin's lymphoma. Blood (ASH Annual Meeting Abstracts). 2009; 114:1714.

79. Wang L, et al. A phase I/II study of lenalidomide in combination with rituximab in relapsed/ refractory mantle cell lymphoma. Blood (ASH Annual Meeting Abstracts). 2009; 114:2719.

80. Chen L, et al. SYK-dependent tonic B-cell receptor signaling is a rational treatment target in diffuse large B-cell lymphoma. Blood. 2008; 111:2230-2237. [PubMed: 18006696]

81. Friedberg JW, et al. Inhibition of Syk with fostamatinib disodium has significant clinical activity in non-Hodgkin lymphoma and chronic lymphocytic leukemia. Blood. 2010; 115:2578-2585. [PubMed: 19965662]

82. Pollyea DA, et al. A phase I dose escalation study of the Btk inhibitor PCi-32765 in relapsed and refractory B cell non-Hodgkin lymphoma and use of a novel fluorescent probe pharmacodynamic assay. Blood (ASH Annual Meeting Abstracts). 2009; 114:3713.

83. Cheson BD, et al. Safety and efficacy of YM155 in diffuse large B-cell lymphoma (DLBCL). J. Clin. Oncol. ASCO Meeting Abstracts. 2009; 27(Suppl.):8502.

84. Tolcher AW, et al. Phase I and pharmacokinetic study of YM155, a small-molecule inhibitor of survivin. J. Clin. Oncol. 2008; 26:5198-5203. [PubMed: 18824702]

85 . Wilson W, et al. ABT-263 activity and safety in patients with relapsed or refractory lymphoid malignancies in particular chronic lymphocytic leukemia (CLL)/small lymphocytic lymphoma (SLL). J. Clin. Oncol. ASCO Meeting Abstracts. 2009; 27(Suppl.):8574.

86. Tse C, et al. ABT-263: a potent and orally bioavailable Bcl-2 family inhibitor. Cancer Res. 2008; 68:3421-3428. [PubMed: 18451170]

87. Wiezorek J, Holland P, Graves J. Death receptor agonists as a targeted therapy for cancer. Clin. Cancer Res. 2010; 16:1701-1708. [PubMed: 20197482]

88. Wu D, et al. No evidence for the JAK2 (v617F) or JAK2 exon 12 mutations in primary mediastinal large B-cell lymphoma. Diagn. Mol. Pathol. 2009; 18:144-149. [PubMed: 19704259] 
89. Melzner I, Weniger MA, Menz CK, Möller P. Absence of the JAK2 v617F activating mutation in classical Hodgkin lymphoma and primary mediastinal B-cell lymphoma. Leukemia. 2006; 20:157158. [PubMed: 16331280]

90. Weniger MA, et al. Mutations of the tumor suppressor gene SOCS-1 in classical Hodgkin lymphoma are frequent and associated with nuclear phospho-STAT5 accumulation. Oncogene. 2006; 25:2679-2684. [PubMed: 16532038]

91. Melzner I, et al. Biallelic deletion within 16p13.13 including SOCS-1 in Karpas1106P mediastinal B-cell lymphoma line is associated with delayed degradation of JAK2 protein. Int. J. Cancer. 2006; 118:1941-1944. [PubMed: 16287070]

92. Joliot V, Cormier F, Medyouf H, Alcalde H, Ghysdael J. Constitutive STAT5 activation specifically cooperates with the loss of p53 function in B-cell lymphomagenesis. Oncogene. 2006; 25:4573-4584. [PubMed: 16532027]

93. Nagy ZS, et al. STAT5 regulation of BCL10 parallels constitutive NFkappaB activation in lymphoid tumor cells. Mol. Cancer. 2009; 8:67. [PubMed: 19709433]

94. Scheeren FA, et al. IL-21 is expressed in Hodgkin lymphoma and activates STAT5: evidence that activated STAT5 is required for Hodgkin lymphomagenesis. Blood. 2008; 111:4706-4715. [PubMed: 18296629]

95. Kube D, et al. STAT3 is constitutively activated in Hodgkin cell lines. Blood. 2001; 98:762-770. [PubMed: 11468177]

96. Alas S, Bonavida B. inhibition of constitutive STAT3 activity sensitizes resistant non-Hodgkin's lymphoma and multiple myeloma to chemotherapeutic drug-mediated apoptosis. Clin. Cancer Res. 2003; 9:316-326. [PubMed: 12538484]

97. Amin HM, et al. Selective inhibition of STAT3 induces apoptosis and G(1) cell cycle arrest in ALK-positive anaplastic large cell lymphoma. Oncogene. 2004; 23:5426-5434. [PubMed: 15184887]

98. Holtick U, et al. STAT3 is essential for Hodgkin lymphoma cell proliferation and is a target of tyrphostin AG17 which confers sensitization for apoptosis. Leukemia. 2005; 19:936-944. [PubMed: 15912144]

99. Yared MA, Khoury JD, Medeiros LJ, Rassidakis GZ, Lai R. Activation status of the JAK/STAT3 pathway in mantle cell lymphoma. Arch. Pathol. Lab. Med. 2005; 129:990-996. [PubMed: 16048411]

100. Ding BB, et al. Constitutively activated STAT3 promotes cell proliferation and survival in the activated B-cell subtype of diffuse large B-cell lymphomas. Blood. 2008; 111:1515-1523. [PubMed: 17951530]

101. Younes A, et al. Phase-I study of the novel oral JAK-2 inhibitor SB1518 in patients with relapsed lymphoma: evidence of clinical and biologic activity. Blood (ASH Annual Meeting Abstracts). 2009; 114:588.

102. LoRusso PM, Boerner SA, Seymour L. An overview of the optimal planning, design, and conduct of phase i studies of new therapeutics. Clin. Cancer Res. 2010; 16:1710-1718. [PubMed: 20215546]

103. Hunsberger S, Rubinstein LV, Dancey J, Korn EL. Dose escalation trial designs based on a molecularly targeted endpoint. Stat. Med. 2005; 24:2171-2181. [PubMed: 15909289]

104. Korn EL. Nontoxicity endpoints in phase I trial designs for targeted, non-cytotoxic agents. J. Natl Cancer Inst. 2004; 96:977-978. [PubMed: 15240771]

105. Barker AD, et al. I-SPY 2: an adaptive breast An overview of the optimal chemotherapy. Clin. Pharmacol. Ther. 2009; 86:97-100. [PubMed: 19440188]

106. Younes A, et al. Safety and tolerability of conatumumab in combination with bortezomib or vorinostat in patients with relapsed or refractory lymphoma. Blood (ASH Annual Meeting Abstracts). 2009; 114:1708.

107. Satoh T, et al. Phase I study of YM155, a novel survivin suppressant, in patients with advanced solid tumors. Clin. Cancer Res. 2009; 15:3872-3880. [PubMed: 19470738]

108. Linardou H, Dahabreh IJ, Bafaloukos D, Murray S. Somatic EGFR mutations and efficacy of tyrosine kinase inhibitors in NSCLC. Nat. Rev. Clin. Oncol. 2000; 6:352-366. [PubMed: 19483740] 
109. Dhomen N, Marais R. BRAF signaling and targeted therapies in melanoma. Hematol. Oncol. Clin. North Am. 2009; 23:529-545. [PubMed: 19464601]

110. Lieberman R. Personalized medicine enters the US marketplace: KRAS, anti-eGFR monoclonal antibodies, and colon cancer. Am. J. Ther. 2009; 16:477-479. [PubMed: 19829092]

111. Eisenhauer EA, et al. New response evaluation criteria in solid tumours: revised RECIST guideline (version 1.1). Eur. J. Cancer. 2009; 45:228-247. [PubMed: 19097774]

112. Cheson BD, et al. Revised response criteria for malignant lymphoma. J. Clin. Oncol. 2007; 25:579-586. [PubMed: 17242396]

113. Flaherty K, et al. Phase I study of PLX4032: Proof of concept for V600e BRAF mutation as a therapeutic target in human cancer. J. Clin. Oncol. ASCO Meeting Abstracts. 2009; 27(Suppl.): 9000.

114. Coiffier B, et al. Rituximab (anti-CD20 monoclonal antibody) for the treatment of patients with relapsing or refractory aggressive lymphoma: a multicenter phase II study. Blood. 1998; 92:1927-1932. [PubMed: 9731049]

115. Leonard JP, et al. Epratuzumab, a humanized anti-CD22 antibody, in aggressive non-Hodgkin's lymphoma: phase I/II clinical trial results. Clin. Cancer Res. 2004; 10:5327-5334. [PubMed: 15328168]

116. O'Mahony D, et al. Yttrium-90 radiolabeled humanized monoclonal antibody to CD25 in refractory and relapsed Hodgkin's lymphoma. Blood (ASH Annual Meeting Abstracts). 2008; 112:231.

117. Viviani S, Bonfante V, Fasola C, Valagussa P, Gianni AM. Phase II study of the histonedeacetylase inhibitor ITF2357 in relapsed/refractory Hodgkin's lymphoma patients. J. Clin. Oncol. ASCO Meeting Abstracts. 2008; 26(Suppl.):8532.

118. Fehniger TA, et al. A phase II multicenter study of lenalidomide in patients with relapsed or refractory classical Hodgkin lymphoma (cHL): preliminary results. Blood (ASH Annual Meeting Abstracts). 2008; 112:2595.

119. Johnston PB, et al. mTOR inhibition for relapsed or refractory Hodgkin lymphoma: promising single agent activity with everolimus (RAD001). Blood (ASH Annual Meeting Abstracts). 2007; 110:2555.

120. Reeder CB, et al. A phase II trial of the oral mTOR inhibitor everolimus (RAD001) in relapsed aggressive non-Hodgkin lymphoma (NHL). Blood (ASH Annual Meeting Abstracts). 2007; 110:121.

121. Ansell SM, et al. Low-dose, single-agent temsirolimus for relapsed mantle cell lymphoma: a phase 2 trial in the North Central Cancer Treatment Group. Cancer. 2008; 113:508-514. [PubMed: 18543327]

122. Goy A, et al. Phase II study of proteasome inhibitor bortezomib in relapsed or refractory B-cell non-Hodgkin's lymphoma. J. Clin. Oncol. 2005; 23:667-675. [PubMed: 15613697]

123. Crump M, et al. Phase II trial of oral vorinostat (suberoylanilide hydroxamic acid) in relapsed diffuse large-B-cell lymphoma. Ann. Oncol. 2008; 19:964-969. [PubMed: 18296419]

124. Younes A, et al. Treatment of relapsed or refractory lymphoma with the oral isotype-selective histone deacetylase inhibitor MGCD0103: interim results from a phase II study. Blood (ASH Annual Meeting Abstracts). 2007; 110:2571.

125. Robertson MJ, et al. Phase II study of enzastaurin, a protein kinase $\mathrm{C}$ beta inhibitor, in patients with relapsed or refractory diffuse large B-cell lymphoma. J. Clin. Oncol. 2007; 25:1741-1746. [PubMed: 17389337] 


\section{Key points}

- Lymphomas are heterogeneous group of malignancies with an estimated 74,000 new cases in 2009 in the USA

- Several agents have been approved by the FDA for the treatment of relapsed non-Hodgkin lymphoma, but no drug has been approved for Hodgkin lymphoma in the past 30 years

- Antibody-drug conjugates and small-molecule inhibitors that target welldefined oncogenic pathways are being evaluated for the treatment of lymphoma and have shown promising results

- In the future, biomarker-driven clinical trials will be important for the development of personalized treatment strategies 
Review criteria

Information for this Review was compiled by searching the PubMed, Highwire Press, and clinicaltrials.gov databases for articles published before May 2010, including abstracts. Search terms included "lymphoma", "Hodgkin", "targeted therapy" and "molecular". Only articles published in english were considered and references were chosen based on the best clinical evidence. 


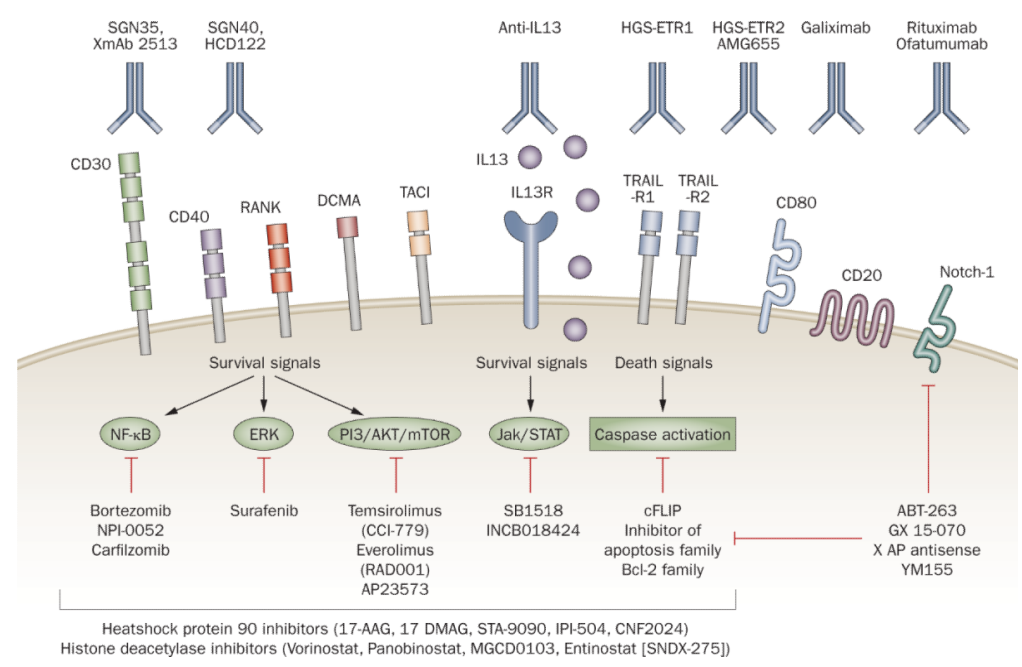

Figure 1.

Targeted therapy for lymphoma treatment. Cancer cells express a variety of receptors and antigens that can be targeted by monoclonal antibodies. Many of these receptors trigger well-defined signaling pathways that promote the growth and survival of lymphoma cells, including NF-KB, ERK, PI3K/Akt/mTOR JAK/STAT, and extrinsic and/or intrinsic apoptosis pathways. These signaling pathways can be targeted by a variety of smallmolecule inhibitors. Abbreviations: ERK, extracellular signal-regulated kinase; JAK/STAT, janus kinase/signal transducer and activator of transcription; NF- $\mathrm{kB}$, nuclear factor-kappa-B; RANK, receptor activator for NF- $\mathrm{KB}$; TRAIL-R1, tumor necrosis factor-related apoptosisinducing ligand death receptor R1. Reproduced from Hematology by Anas Younes.

Copyright 2009 by American Society of Hematology (ASH). Reproduced with permission of American Society of Hematology (ASH) in the format Journal via Copyright Clearance Center. 


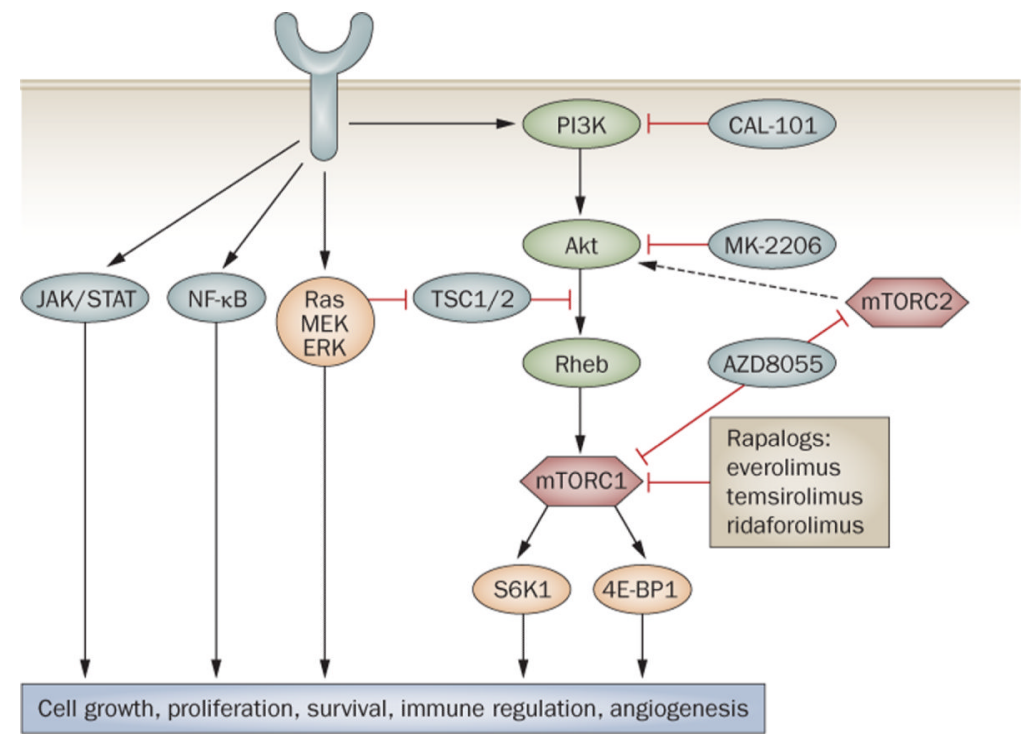

Figure 2.

Targeting the PI3K/Akt/mTOR pathway to treat lymphoma. Pharmacological inhibition of mTORC1 with rapalogs has produced clinical responses in patients with relapsed nonHodgkin lymphoma and classic Hodgkin lymphoma. Second-generation mTOR inhibitors and inhibitors of upstream molecules such as Akt and PI3K are currently in clinical trials. Frequently, cancer cells have several activated survival pathways, including the MEK/ERK, NF- $\mathrm{KB}$, and JAK/STAT pathways. A combination of small molecules may be required to target these pathways. Abbreviations: ERK, extracellular signal-regulated kinase; JAK, Janus kinase; MEK, mitogen-activated protein kinase; mTOR, mammalian target of rapamycin; NF-KB, nuclear factor-kappa-B; PI3K, phosphatidylinositol 3-kinase; STAT, signal transducer and activator of transcription; TSC, tuberous sclerosis complex.

Reproduced from Hematology by Anas Younes. Copyright 2009 from the American Society of Hematology (ASH). Reproduced with permission of American Society of Hematology (ASH) in the format Journal via Copyright Clearance Center. 


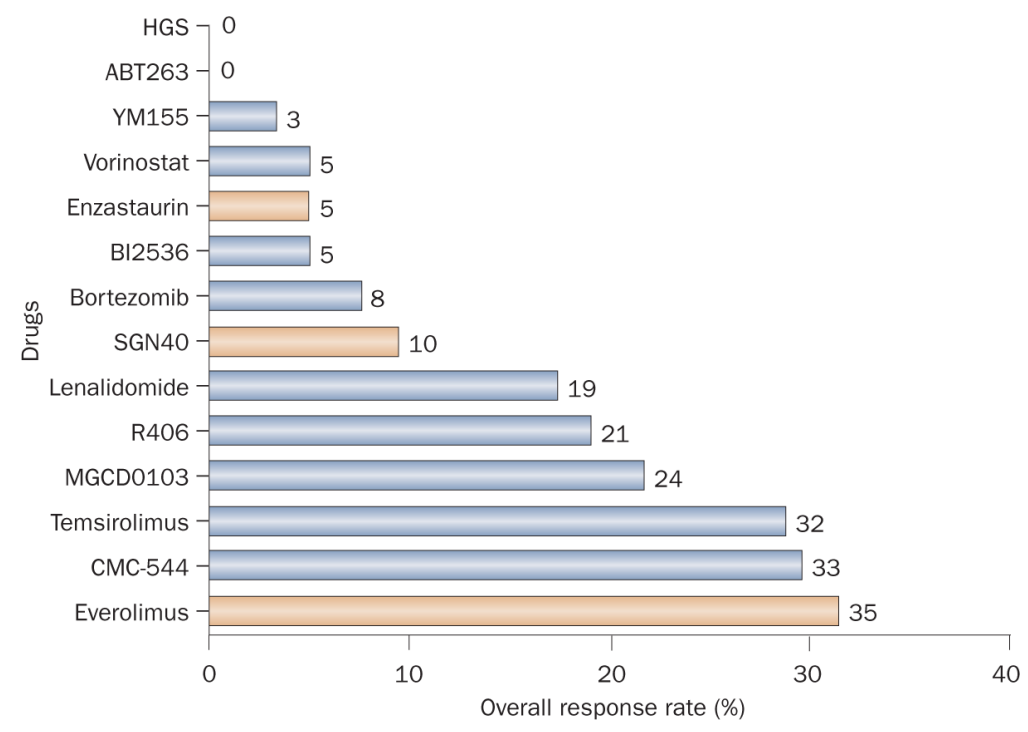

Figure 3.

Summary of single agents with activity in patients with relapsed diffuse large B-cell lymphoma. This chart is not meant to compare drugs with one another because these data are derived from a variety of phase I and II studies, some of which are ongoing. Single-agent overall response rates of targeted agents rarely exceed 30\%. Drugs that are shown in yellow are currently in pivotal trials. 
Table 1

Selected antibodies in development for B-cell lymphoma

\begin{tabular}{|c|c|c|c|}
\hline \multirow[t]{2}{*}{ Antibody } & \multirow[t]{2}{*}{ Target } & \multicolumn{2}{|l|}{ Overall response rate $(\%)$ by histology } \\
\hline & & Follicular lymphoma or indolent lymphoma & Diffuse large B-cell lymphoma \\
\hline \multicolumn{4}{|l|}{ Naked unconjugated antibodies } \\
\hline Rituximab $^{9,114}$ & $\mathrm{CD} 20$ & 50 & 30 \\
\hline Ofatumumab $^{7}$ & $\mathrm{CD} 20$ & 42 & Not included \\
\hline Epratuzumab $^{11,115}$ & $\mathrm{CD} 22$ & 18 & 10 \\
\hline Dacetuzumab $^{20}$ & $\mathrm{CD} 40$ & Not included & 10 \\
\hline Mapatumumab $^{22}$ & TRAIL-R1 & 12 & 0 \\
\hline \multicolumn{4}{|l|}{ Antibody-drug conjugates } \\
\hline CMC- $544^{28^{*}}$ & $\mathrm{CD} 22$ & 68 & 15 \\
\hline SAR3419 $30^{*}$ & CD19 & 24 & 0 \\
\hline \multicolumn{4}{|l|}{ Combination antibodies } \\
\hline Rituximab plus epratuzumab ${ }^{17}$ & $\mathrm{CD} 20, \mathrm{CD} 22$ & 64 & 47 \\
\hline Rituximab plus CMC-54429* & $\mathrm{CD} 20, \mathrm{CD} 22$ & 84 & 80 \\
\hline
\end{tabular}

Results are shown in patients with relapsed disease. Response rates to single-agent rituximab, which is approved by the FDA, are shown as a reference.

Abbreviation: TRAIL-R1, tumor necrosis factor-related apoptosis-inducing ligand death receptor R1.

*alicheamicin is the drug conjugate.

tDM4 is the drug conjugate. 


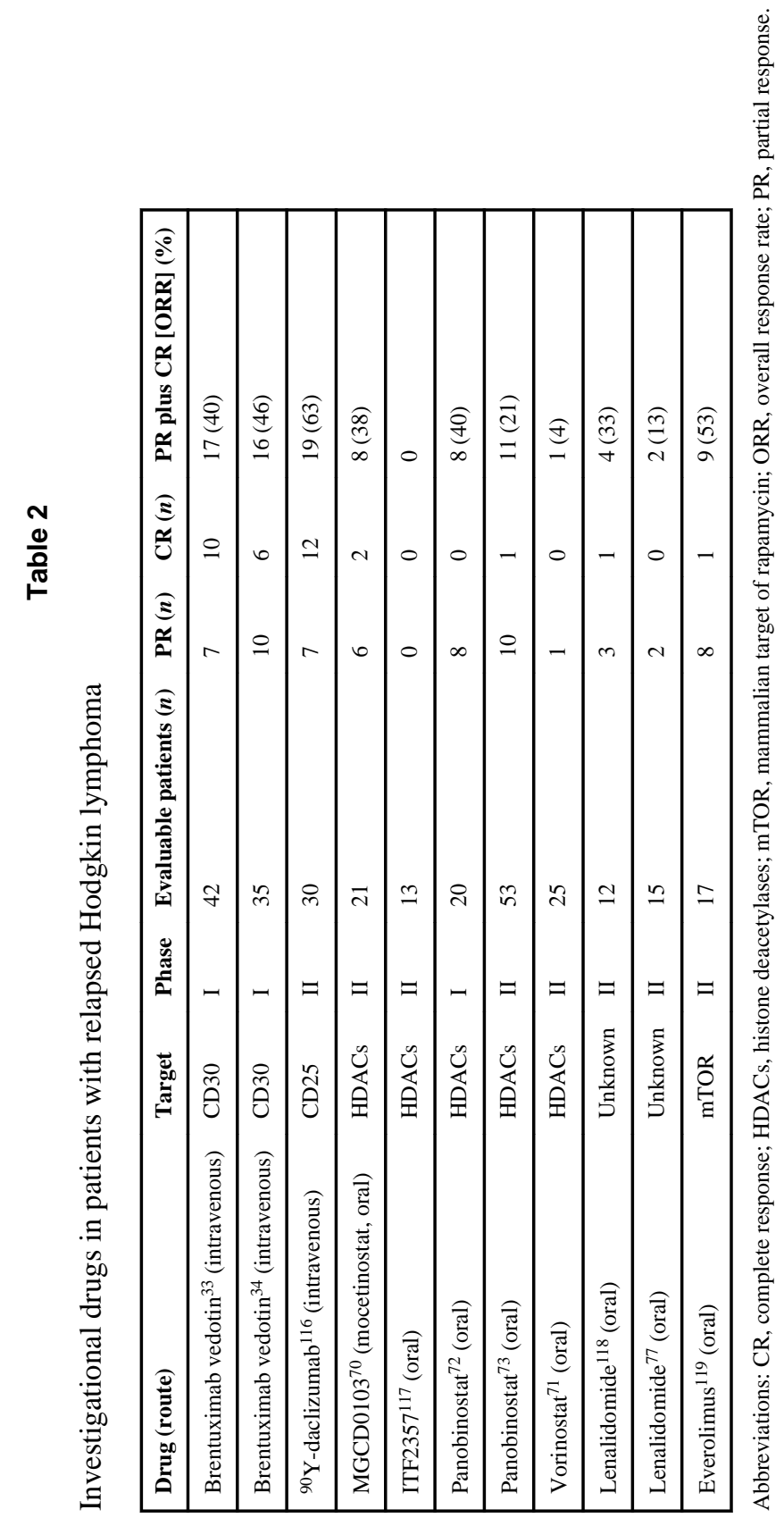

Nat Rev Clin Oncol. Author manuscript; available in PMC 2011 October 13. 


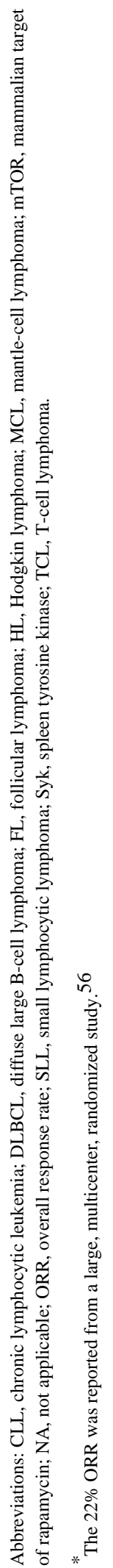

Nat Rev Clin Oncol. Author manuscript; available in PMC 2011 October 13. 


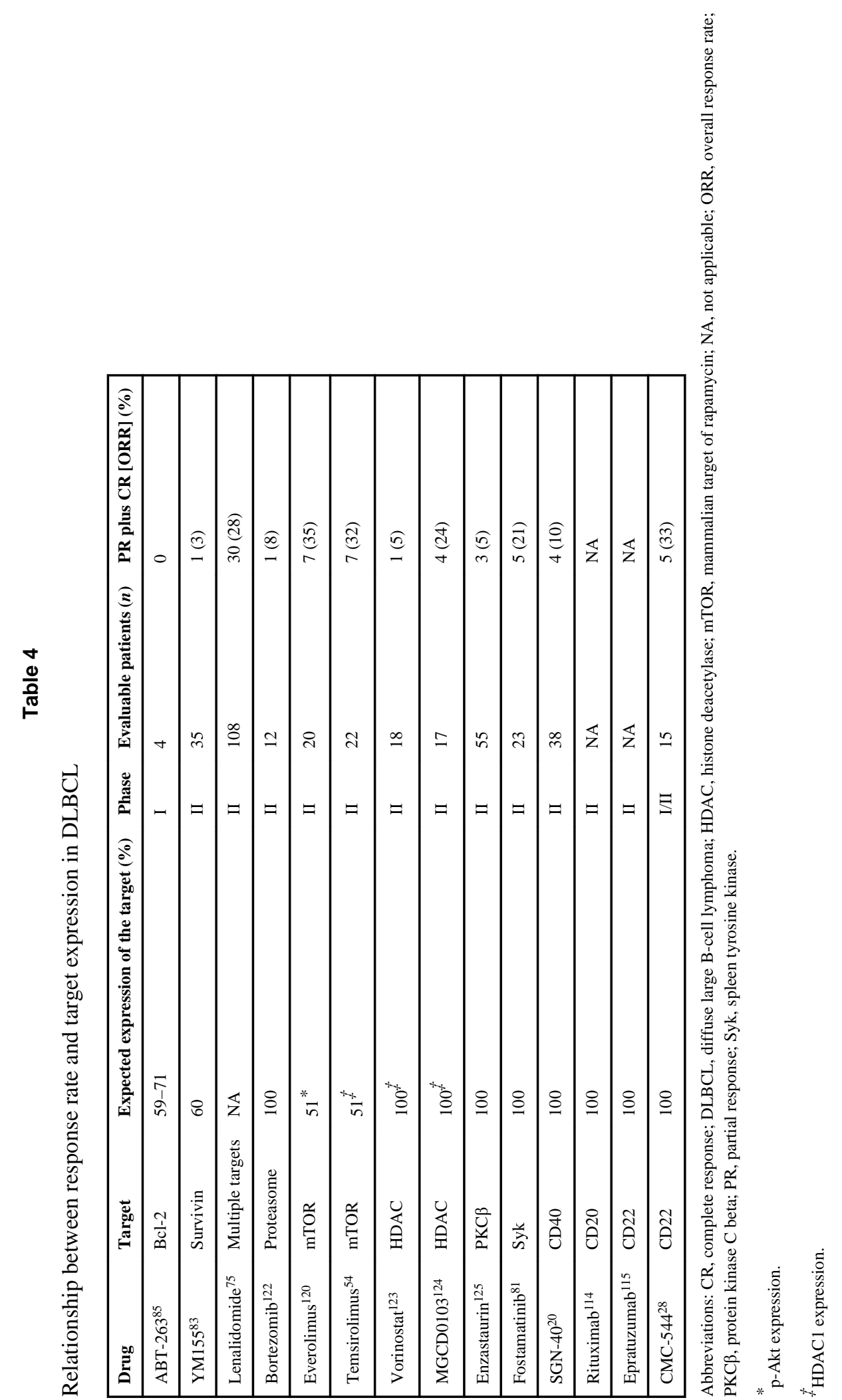

